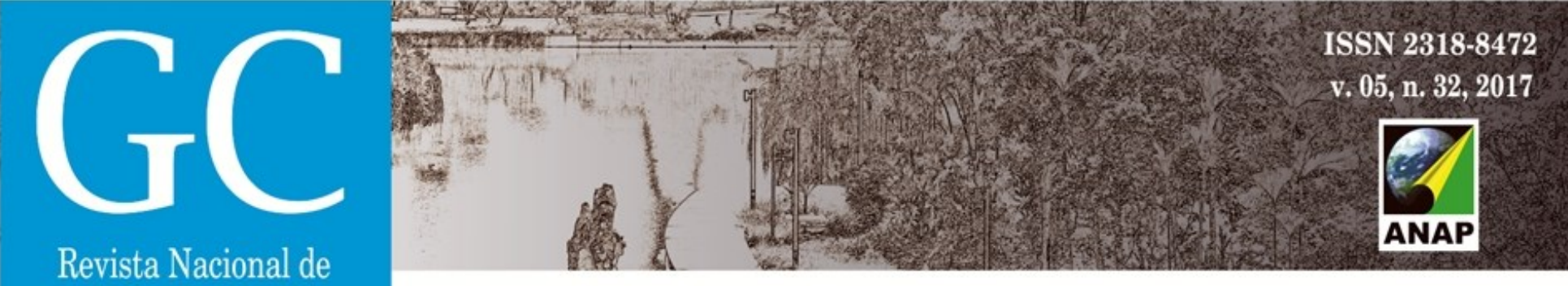

\title{
Os Parques Urbanos na História da Cidade: percepção, afetividade, imagem e memória da paisagem
}

The Urban Parks in the City History:

perception, affectiveness, image and memory of the landscape

Los Parques Urbanos en la Historia de la Ciudad:

percepción, afectividad, imagen y memoria del paisaje

Hérica Maria Saraiva Melo

Psicóloga Doutoranda, CTT/UFPI, Brasil. hericamelo@ufpi.edu.br

\section{Wilza Gomes Reis Lopes}

Professora Doutora, UFPI, Brasil. wilzalopes@hotmail.com

\section{Dayanne Batista Sampaio}

Professora Mestra, UFPI, Brasil. dayannebsampaio@hotmail.com 


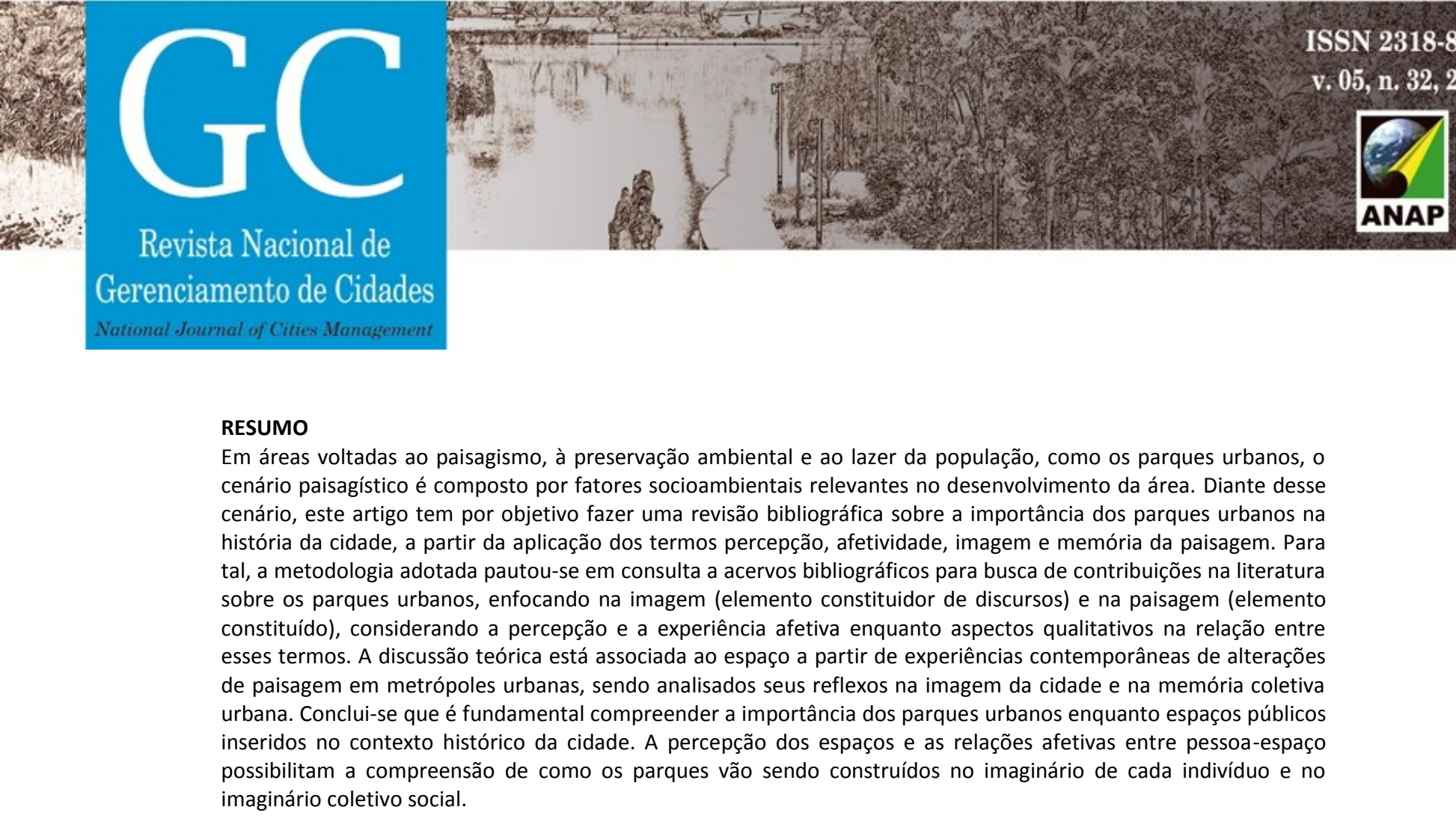

\section{RESUMO} cenário, este artigo tem por objetivo fazer uma revisão bibliográfica sobre a importância dos parques urbanos na a metodologia adotada pautou-se em consulta a acervos bibliográficos para busca de contribuições na literatura de paisagem em metrópoles urbanas, sendo analisados seus reflexos na imagem da cidade e na memória coletiva imaginário coletivo social.

PALAVRAS-CHAVE: Espaço público. Parques. Paisagem.

\section{ABSTRACT}

In areas that focus on landscaping, environmental preservation and leisure of the population, such as urban parks, the landscape scenario is composed of relevant social and environmental factors in the development of the area. In view of the scenario, this article aims to make a bibliographical review about the importance of urban parks in the city's history, based on the application of the terms perception, affectivity, image and memory of the landscape. To that end, an element of the adopted methodology was based on a bibliographical collection to search for contributions in the literature about urban parks, focusing on the image (constituent element of discourses) and in the landscape (constituted element), considering the perception and the affective experience as qualitative aspects in the relation between these terms. The theoretical discussion is associated with space from contemporary experiences of landscape changes in urban metropolis, being analyzed its reflections in the image of the city and the urban collective memory. It is concluded that it is fundamental to understand the importance of urban parks as public spaces inserted in the historical context of the city. The perception of spaces and affective relations between person-space allow the understanding of how parks are being built in the imaginary of each individual and in the collective social imaginary.

KEYWORDS: Public space. Parks. Landscape.

\section{RESUMEN}

En áreas orientadas al paisajismo, a la preservación ambiental y al ocio de la población, como los parques urbanos, el escenario paisajístico está compuesto por factores socioambientales relevantes en el desarrollo del área. En este contexto, este artículo tiene por objeto hacer una revisión bibliográfica sobre la importancia de los parques urbanos en la historia de la ciudad, a partir de la aplicación de los términos percepción, afectividad, imagen y memoria del paisaje. Para ello, la metodología adoptada se orientó en consulta a acervos bibliográficos para la búsqueda de contribuciones en la literatura sobre los parques urbanos, enfocando en la imagen (elemento constituyente de discursos) y en el paisaje (elemento constituido), considerando la percepción y la experiencia afectiva en cuanto aspectos cualitativos en la relación entre estos términos. La discusión teórica está asociada al espacio a partir de experiencias contemporáneas de cambios de paisaje en metrópolis urbanas, siendo analizados sus reflejos en la imagen de la ciudad y en la memoria colectiva urbana. Se concluye que es fundamental comprender la importancia de los parques urbanos como espacios públicos insertados en el contexto histórico de la ciudad. La percepción de los espacios y las relaciones afectivas entre persona-espacio posibilita la comprensión de cómo los parques van siendo construidos en el imaginario de cada individuo y en el imaginario colectivo social.

PALABRAS CLAVE: Espacio público. Parques. Paisaje. 


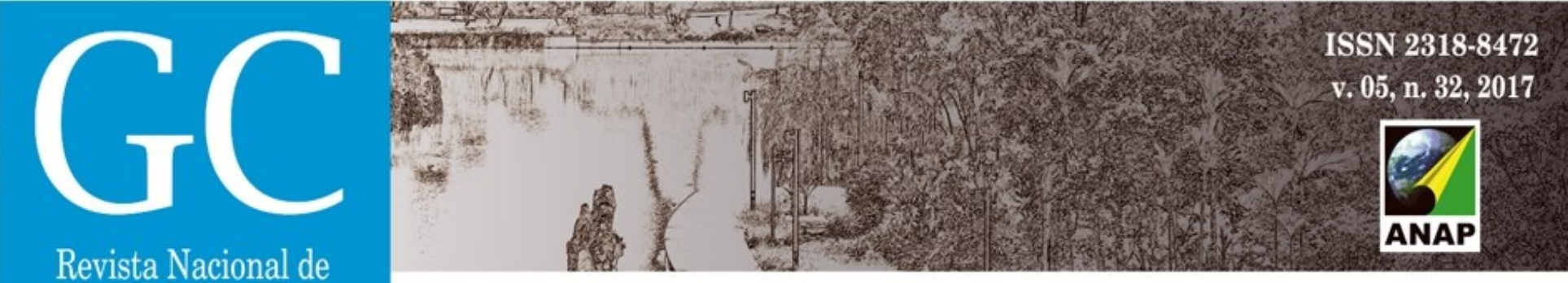

Gerenciamento de Cidades

Paiva e Gonçalves (2002), a paisagem passa a ser avaliada como uma interação de diversos fatores, envolvendo os valores ecológicos fundamentais para a qualidade de vida.

A importância do vegetal na paisagem urbana está no lazer, pois as diversas categorias de espaços verdes urbanos favorecem a aproximação do homem urbano com a natureza. Em outras palavras, é o estado de satisfação física, psíquica ou moral, por fim, o bem-estar e a qualidade de vida. Portanto, faz-se imprescindível a discussão de paisagem urbana para o planejamento das cidades, uma vez que a qualidade da paisagem vai influenciar a qualidade de vida das pessoas. Portanto, os significados da "paisagem" revelam que ela não é apenas a condição estática de um espaço observado por um sujeito. É também a produção do espaço e a representação do espaço por estes mesmos sujeitos, o que insere uma perspectiva dinâmica e diacrônica em sua conceituação e significados. Antes de aprofundar tais aspectos, faz-se necessário compreender o percurso conceitual dos espaços livres e das áreas públicas, enquanto elementos essenciais da paisagem urbana.

\subsection{Espaços Livres e Áreas Públicas: um percurso conceitual}

Os espaços livres, conforme Magnoli (2006), são todos os espaços não ocupados por volume edificado, espaço solo, espaço-água, espaço luz ao redor das edificações e são responsáveis pela articulação do tecido urbano, além de representarem lugares onde se traçam relações sociais. Sanchotene (2004) considera que os espaços livres são as áreas não edificadas de uma cidade, de propriedade do Município, Estado, União ou de particulares, independentes de sua destinação de uso. Quando destinados à preservação ou implantação de vegetação ou ao lazer público, passam a se chamar áreas verdes, as quais podem ser praças, parques, jardins públicos, arborização urbana, etc. podendo ter vegetação de ocorrência natural ou implantada. Nesse sentido, é interessante apresentar a classificação de Tardin (2008), que considera os espaços livres a partir de quatro pontos de vista. Do ponto de vista urbano, como importantes elementos na definição do uso e ocupação do solo, sendo áreas que viabilizam a criação de articulação espacial entre as partes do território. Já do ponto de vista sociocultural, os espaços livres possibilitam o encontro, o lazer, o descanso, o espaço de construção da cidadania. Do ponto de vista perceptivo, é o lugar de criação da identidade visual, que favorece a apropriação do espaço e a transformação do espaço em lugar. Enquanto que, do ponto de vista biofísico, são fundamentais para a manutenção e o equilíbrio ambiental. Segundo Macedo (1999), os espaços livres urbanos ajudam a construir a paisagem urbana da cidade como um produto, porque resulta de um processo social de ocupação e gestão de determinado território.

Quanto às áreas públicas, Romero $(2001$, p. 29) explica que os espaços públicos "condicionam os espaços construídos, que às vezes thes conferem suas formas, seus relevos, suas características. São elementos essenciais da paisagem urbana que constituem os espaços de vida, que 'percebem' a cidade". Apresentam diferentes tipologias, como ruas, praças, avenidas, 


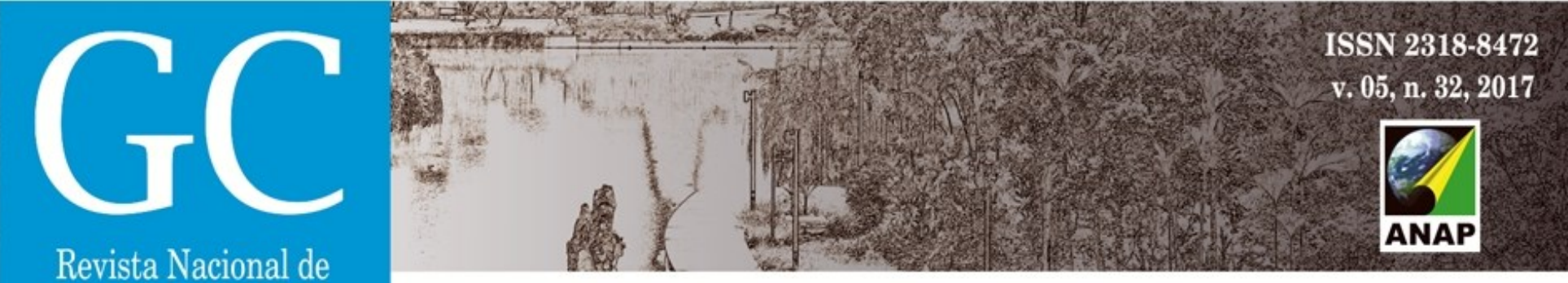

Gerenciamento de Cidades

parques; que se organizam, formando sistemas, sendo a sistematização destes espaços responsável pela estruturação do tecido urbano em qualquer cidade (SERPA, 1997).

A partir dessas definições sobre os espaços livres e as áreas públicas, pretende-se também compreender os parques urbanos, a fim de investigar e discutir o conceito e a abrangência funcional dos mesmos no contexto histórico da cidade.

\subsection{A importância dos Parques Urbanos na História da Cidade}

O ritmo acelerado da vida cotidiana, o trânsito, a violência, a poluição, o excesso de asfalto e concreto fazem com que a vida nas cidades seja cada vez mais estressante e, até mesmo, perigosa. A busca por ambientes naturais tem aumentado bastante nos últimos anos. Os parques passaram a ser considerados logradouros voltados ao conforto físico e psicológico do cidadão e da melhoria ambiental da cidade. Com o crescimento rápido urbano e problemas dele advindos, torna-se necessário pensar em estratégias de proteção e preservação dos espaços potenciais para a conservação de suas características naturais, em busca de um aperfeiçoamento ambiental e da vida. Assim, surgem os parques, enquanto espaços livres, essencial a essa conjectura de vida moderna dos habitantes, inserindo no planejamento um olhar direto aos parques como estratégia ao desenvolvimento das cidades.

Parques urbanos são definidos como espaços livres públicos urbanos, com dimensões significativas e predominância de elementos naturais, com ambiente equipado para recreação, com paisagem rica em elementos naturais e com independência espacial no que se refere à malha urbana (KLIASS, 1993; GONÇALVES, 1994). Constituem-se elementos do espaço urbano, sendo constantemente experienciados e (re)construídos. Nesses espaços ocorre o alívio das tensões ocasionadas, sobretudo, pelo acelerado ritmo de vida, funcionando como "organismos vivos". Dessa forma, analisar o espaço urbano, segundo Carlos (2003, p.79), "significa pensar o homem enquanto ser individual e social no seu cotidiano, no seu modo de viver, agir e pensar". Sabe-se que, no Brasil, a origem dos parques urbanos é do século XVIII e advém da necessidade de proteção de áreas para contemplação e lazer e da organização de jardins e passeios públicos voltados ao interesse da coroa portuguesa nas potencialidades econômicas da natureza brasileira (SEGAWA, 1996, p. 16). Ao avaliar o tempo histórico, percebe-se que os parques se diferenciam quanto aos objetivos e papéis e/ou das necessidades vivenciadas pela sociedade.

Na atualidade, eles têm a função social, estética, ecológica e de proporcionar um espaço onde os cidadãos possam gozar os seus tempos livres, o que é uma necessidade cada vez mais evidente para a população urbana, estampando suas atribuições no desenvolvimento dos planos e projetos.

Segundo Macedo e Sakata (2003), os parques podem ser considerados espaços de uso público, destinados à recreação de massa, capazes de incorporar intenções de conservação e cuja 


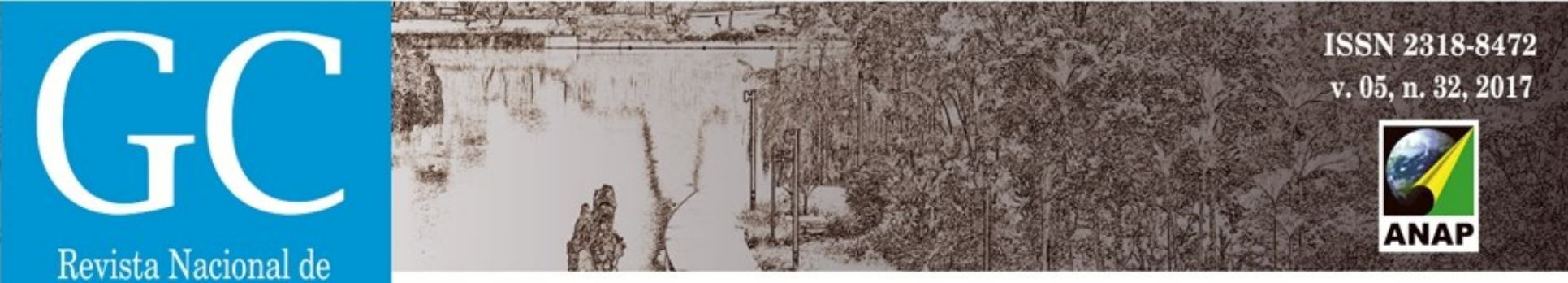

Gerenciamento de Cidades

posteriormente, seja possível compreender da percepção das pessoas sobre o espaço e, consequentemente, a maneira como a afetividade se configura na relação pessoa-espaço.

Em seguida, será analisada a paisagem nos parques urbanos, considerando a existência dos vínculos afetivos dos seres humanos para com os lugares e suas paisagens. Dessa forma, é fundamental compreender a paisagem considerando os aspectos qualitativos desses espaços, a saber: percepção e afetividade.

\subsection{A Paisagem nos Parques Urbanos: da percepção à afetividade}

No século XVIII, surgiu a educação do olhar para a paisagem. Os Passeios vão aparecendo em várias cidades, como é o caso do Passeio Público de Lisboa e do Passeio Público do Rio de Janeiro, que é considerado por Segawa (1996), inovador do ponto de vista da paisagem.

Berque (1994) afirma que a paisagem reside não somente no objeto (o meio ambiente ou suporte físico) nem somente no sujeito (a ação humana), mas na complexa interação entre ambos. Essa interação coloca em jogo diversas escalas de tempo e espaço e envolve tanto o estabelecimento mental da realidade quanto o estabelecimento material das coisas, ou seja, a paisagem é uma relação complexa entre o suporte físico e as pessoas considerando o caráter subjetivo presente nessa relação.

Sabe-se que as demandas sociais são inúmeras e complexas, pois a cidade é conformadora de uma quase incompreensível teia de relações entre seus diversos atores (KUHNEN, 2009). Assim, deve-se entender que há uma relação dialética entre homem e ambiente e que desvendar o ambiente experienciado é uma tarefa complexa, pois o mundo vivido não é absolutamente óbvio e seus significados não se apresentam por si mesmos. Para Schroeder (2002), é necessário interpretar o espaço a partir de suas representações cognitivas e significativas, apreendendo-o como percebido.

Claval (2004) considera a paisagem como resultado de uma subjetividade decorrente, entre outros fatores, do olhar humano sobre o meio ambiente. Essa subjetividade presente na paisagem e citada pelo autor pode ser resultante de formas simbólicas acumuladas em nosso inconsciente, de uma imposição silenciosa de experiências anteriores. Para Cauquelin (2007) tais formas simbólicas funcionam como "dobras internas", ou seja, elementos e valores de nossa cultura que estão enraizados em nós, dos quais não nos damos conta e que dão suporte e estruturam o nosso modo de enquadrar as paisagens.

Desse modo, a percepção surge como um fator fundamental na formação das paisagens, pois estas se revelam diferentemente a cada observador. A percepção é um fator fundamental para a avaliação da relação do homem com o espaço onde ele vive e como ele visualiza o mundo externo. O estudo da percepção vem auxiliando na compreensão da relação homem/natureza, homem/ambiente construído, no processo de gestão e planejamento participativo em diversos lugares. 


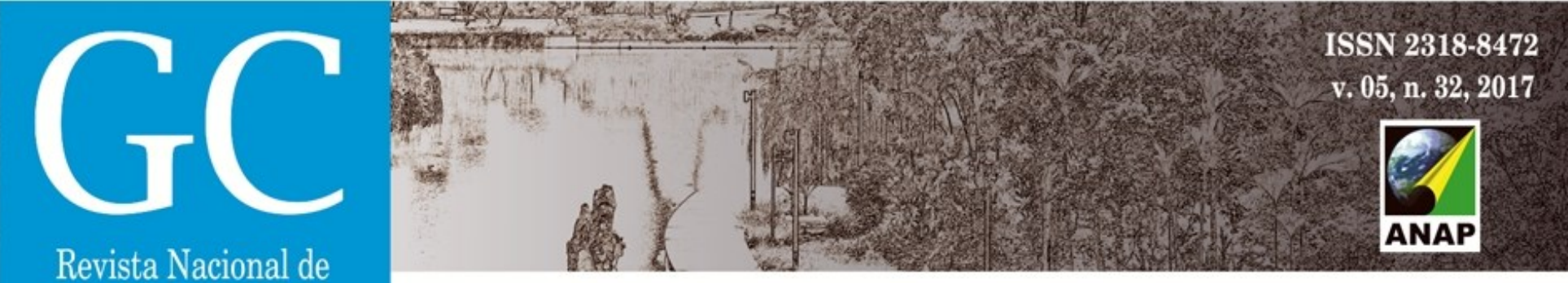

Gerenciamento de Cidades

representações sociais, visões de mundo e outras formas de categorias sociais que a autora denomina "estima de lugar". Esta pode assumir aspectos de positividade ou negatividade, conforme o quadro de afetos, percepções e significados que o sujeito constrói em sua interrelação social e espacial.

Desta maneira a paisagem é dinâmica, está em constante construção e a ela são sempre somadas novas interferências humanas permeadas por símbolos de nossa cultura. Conforme afirma Calvino (1990) a cidade não é feita somente de pedras, mas de homens e ela revela os valores e os símbolos da cultura da população.

Observa-se, de acordo com Leão (2010), que a relação existente entre os diversos elementos da paisagem, formada por fatores físicos, sociais, representações e significados denotam uma intenção de paisagem possível de ser revelada e que requer ações de conservação que a tomem como uma unidade de paisagem. A preservação dessa paisagem urbana deve marcar a identidade do local e da população e deve permitir que, ao se observar essa paisagem mais atentamente, ela conte sua história e, consequentemente, a história dos moradores da cidade.

Quando aplicada aos lugares, os afetos tornam-se mediadores da construção de sujeitos que sentem, pensam e agem partindo de uma racionalidade ético-afetiva. Cidadãos que se identificam com o lugar facilitam processos de apropriação do espaço, e consequentemente ocorre uma diminuição dos sentimentos de medo e insegurança.

A percepção e a afetividade para com o lugar possibilitam entender a ideia de paisagem urbana como categoria descritiva, mas também enquanto discurso da imagem, constituindo-se e sendo constitutiva da memória, cujos limites cognitivos estão orientados pela experiência. Em seguida, serão analisadas a imagem (paisagem da memória) e a memória da paisagem, para uma compreensão sistêmica dos processos sociais e espaciais.

\subsection{A Paisagem nos Parques Urbanos: da imagem à memória da paisagem}

As relações estabelecidas entre pessoa-espaço estão atravessadas pelo conceito de percepção e experiência afetiva, em conjunto com o estabelecimento das articulações entre memória e paisagem; seja como experiência acumulada cujo sentido remete imediatamente a memória e sua incidência nas práticas do lugar (CERTEAU, 1996). Experiência assume o nível mais abstrato de referência do fenômeno em análise, sendo empregada como conceito que remete ao experienciado ou experimentado, tornando-se acessível através do discurso.

A ideia de imagem na paisagem urbana, segundo Martins e Marzulo (2014), incide nos processos de instauração e cognição das espacialidades. A partir da virada visual a imagem passa a ser tratada na sociedade contemporânea como discurso, ou seja, passa a ser entendida como constituidora de sentidos e significados. Seu entendimento deixa de ser simplesmente representação da realidade para posicionar-se como categoria abstrata capaz de estabelecer novos sentidos na disputa pela instauração da materialidade. 


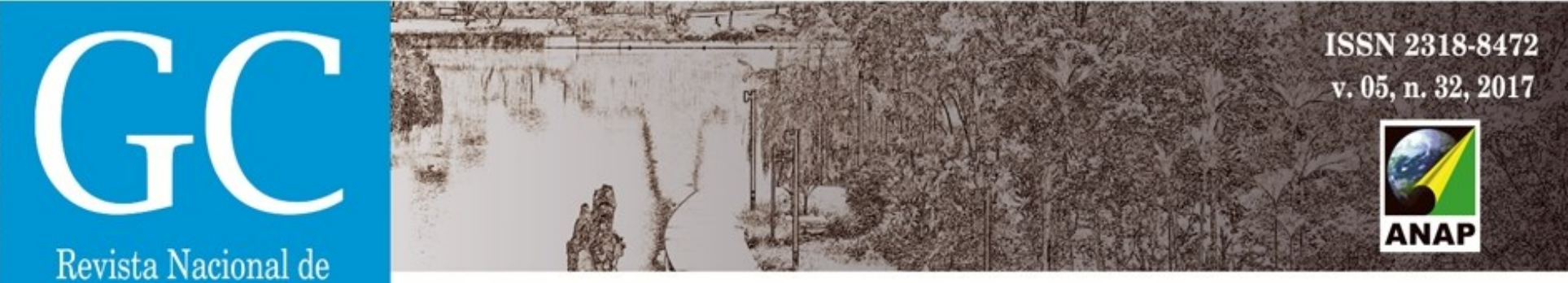

Gerenciamento de Cidades

Entende-se que a imagem está inserida tanto nos processos analíticos como operativos de apropriação do espaço. No momento as imagens deixam de ser interpretadas por seu aspecto figurativo e passam a ser tratadas por seu aspecto discursivo e, logo, de incidência sobre as análises espaço-territoriais (MARZULO; HECK, 2017).

Interpretar as imagens como discursos acrescenta informações à análise de paisagem que tornam sua estrutura, função, forma, dinâmica, elementos e experiência mais complexos e dificilmente indissociáveis entre si. Toda dinâmica de construção de identificação é inerentemente espacial, seja ela materializada no território em forma de instituições, seja na construção simbólica e no imaginário de diferentes grupos culturais (HAESBAERT, 2007). Logo, apropriar-se de um território é ter acesso tanto às realidades visíveis (política, econômica) quanto aos poderes invisíveis (cultura).

Da mesma forma, o debate contemporâneo sobre a memória também tem recaído sobre os processos de sua construção. A centralidade da relação entre memória e paisagem dar-se a partir da memória coletiva (HALBWACHS, 2006), em particular na abordagem de memória como narrativa, cujo sentido se constitui desde a espacialidade e em sua relação intrínseca à questão da imagem a partir do estabelecimento do discurso imagético como recurso constituidor e, também, de afirmação de determinado sentido da memória pelo estabelecimento de determinada imagem.

De acordo com Pollack (1992) os elementos constitutivos da memória, individual ou coletiva, são os acontecimentos vividos pessoalmente e também pelo grupo ou coletividade à qual a pessoa se sente pertencer. A memória se constituindo pelos lugares particularmente ligados a uma experiência privada ou social enquanto lugares da memória pública. Torna-se fenômeno construído, uma vez que sua constituição decorre de valorações sociopolíticas de determinado momento histórico. Ao afirmar-se que a memória é um fenômeno construído desde imagens, ao se tratar da memória herdada enquanto produção e incorporação de legado de imagens fica estabelecida a estreita ligação entre memória e constituição biográfica.

A paisagem urbana, nesse sentido, passa então a romper com sua conceitualização de origem geomorfológica para se afirmar como aspecto cultural, em virtude de processos de construção desde imagens e memórias que a legitimam, fortalecendo o vínculo entre imagem, memória e paisagem provocando o debate sobre as interpenetrações destas categorias. Por isto, a noção de imagem é entendida como norteadora da categoria paisagem.

A seguir, serão apresentadas considerações finais sobre a discussão teórica realizada, entendendo que a paisagem urbana deve ser analisada a partir da percepção, da afetividade, da imagem da cidade e da memória coletiva urbana. 


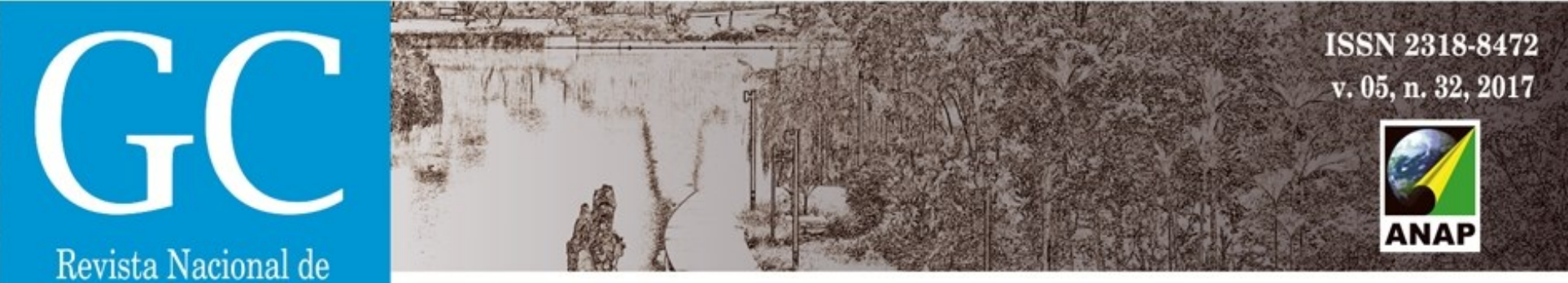

Gerenciamento de Cidades

dos parques urbanos. Com relação à análise da memória, especialmente tratando-se da pósmemória, é fundamental que o espaço tenha um significado histórico para a cidade.

Considera-se necessário a promoção da interação entre ser humano e natureza na cidade. E isto vai além de uma política pública que enfatize unicamente o valor da biodiversidade ou exclusivamente se preocupe em garantir um meio ambiente saudável. Em um mundo em que a maior parte da população já vive no meio urbano e que se tornará cada vez mais urbanizado, é necessário se pensar nas maneiras que permitirão (re)aproximar as pessoas aos elementos naturais da paisagem.

O conceito de "paisagem" guarda diversas dicotomias, sendo um conceito elástico, que facilmente pode ser apropriado a discursos ideológicos. O que envolve aspectos da identidade. Só se compreende determinada abordagem ou recorte da paisagem se está claro o que se entende por cultura dentro do contexto em que vai se estudar. Por isso mesmo há, de forma inegável, uma interface entre natureza, cultura e história.

Conclui-se que é fundamental compreender a importância dos parques urbanos enquanto espaços públicos inseridos no contexto histórico da cidade. A percepção dos espaços e as relações afetivas entre pessoa-espaço possibilitam a compreensão de como os parques vão sendo construídos no imaginário de cada indivíduo e no imaginário coletivo social. A análise de aspectos imagéticos da paisagem está relacionada de forma intrínseca a aspectos da memória individual e coletiva que se têm do lugar. A cidade e seus espaços, portanto, constitui-se como espaço privilegiado ao exercício de reflexão acerca do ser humano e da vida cotidiana enquanto prática sócio-espacial-temporal. É, a relação que o indivíduo mantém com o espaço que o cerca, o que mais influencia na sua forma de uso, significação e valorização. Portanto, é sobre essa ligação que é preciso reconhecer as marcas histórias dos espaços e o que estes representam na memória coletiva de seus habitantes.

\section{REFERÊNCIAS BIBLIOGRÁFICAS}

AMORIM FILHO, O. B. A evolução do pensamento geográfico e a fenomenologia. Sociedade e Natureza, Uberlândia, n. 21 e 22, p. 67-87, jan/dez. 1999.

BARGOS, D. C.; MATIAS, L. F. Áreas verdes urbanas: um estudo de revisão e proposta conceitual. REVSBAU, Piracicaba, v. 6, n. 3, p. 172-188, 2011.

BERQUE, A. Paisagem-marca, paisagem-matriz: elementos da problemática para uma geografia cultural. In: CORREAA, R. L.; ROSENDAHL, Z. (org). Paisagem, tempo e cultura. Rio de Janeiro: EdUERJ, 1998.

BOLÓS Y CAPDEVILA, M. Manual de ciencia del paisage: teoria, métodos Y aplicaciones. Barcelona: Masson S. A. 1992.

BOMFIM, Z. A. Cidade e afetividade: estima e construção de mapas afetivos de Barcelona e São Paulo. Fortaleza, Edições UFC, 2010. 



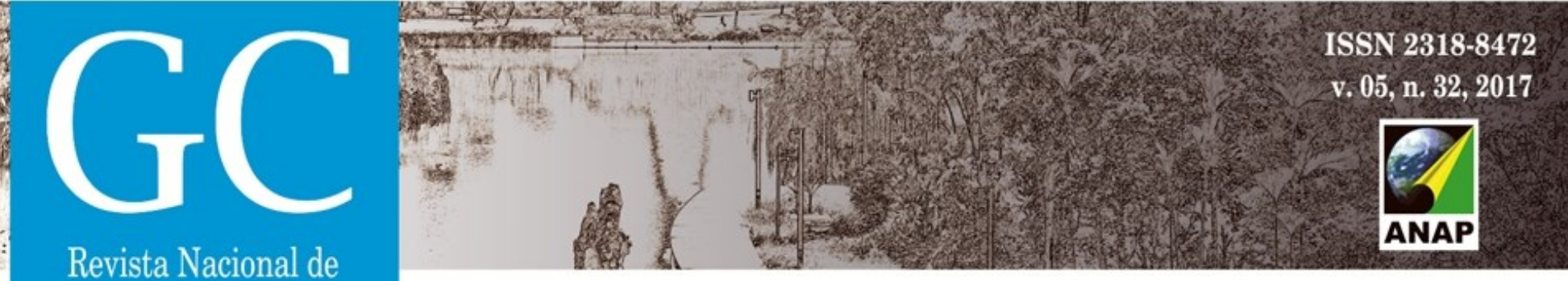

Gerenciamento de Cidades

Percepção Ambiental. In: CAVALCANTI, S. E.; ELALI, G. A.(Org.). Temas Básicos em Psicologia Ambiental. Petrópolis/RJ: Editora Vozes, 2011.

LEÃO, T. M. S. A história da paisagem da Praça Dom Pedro II em Maceió - AL. 2010. 141 f. Dissertação (Mestrado em Desenvolvimento Urbano) - Universidade Federal de Pernambuco, 2010.

LEFEBVRE. H. A Revolução urbana. Belo Horizonte: Editora da UFMG, 1999.

MACEDO, S. S. Quadro do Paisagismo no Brasil. Coleção Quapá. V. 1. São Paulo: 1999.

MACEDO, S. S.; SAKATA, F. G. Parques urbanos no Brasil. 2. ed. Coleção Quapá. São Paulo: Edusp, 2003.

MACHADO, L. P. A Praça da Liberdade na percepção do usuário. Revista Geografia e Ensino, Belo Horizonte, v. 5, n. 1, p. 18-33, 1993.

MAGNOLI, M. M. O parque no desenho urbano. Paisagem ambiente: Ensaios, Especial Miranda Magnoli, n. 21, 2006.

MARTEN, G. G. Human Ecology: Basic Concepts for Sustainable Development. Earthscan Publications, 2001.

MARTINS, M.; MARZULO, E. P. A imagem do Uruguai: uma leitura da paisagem construída pelo cinema contemporâneo. In: Anais do Fórum Patrimônio: Ambiente Construído e Patrimônio Sustentável - Paisagem Cultural. Belo Horizonte, v. 7, n. 1, 2014.

MARZULO, E. P.; HECK, M. A. Da imagem à memória da paisagem. In: Anais do XVII ENANPOU. Sessão temática 6: espaço, identidade e práticas sócio-culturais. São Paulo, 2017.

MEINIG, D. W. O olho que observa: dez versões da mesma cena. Espaço e Cultura, n. 13, p. 35-46, 2002.

MERLEAU-PONTY, M. Fenomenologia da percepção. São Paulo: Martins Fontes, 1994.

MOSER, G. Psicologia ambiental no novo milênio: integrando a dinâmica cultural e a dimensão temporal. In: TASSARA, E. (Org.). Panoramas interdisciplinares para uma psicologia ambiental do urbano. São Paulo: EDUC/ FAPESP, 2001. p.189-210.

PAIVA, H. N.; GONÇALVES, W. Florestas urbanas: planejamento para melhoria da qualidade de vida. Viçosa, Minas Gerais: Aprenda Fácil, 2002.

PEREIRA, D. A. Valores e sentidos atribuídos à paisagem ambiental urbana no Parque Ecológico Olhos D'água em Brasília - DF. 2013. 107f. Dissertação (Mestrado em Educação) - Programa de Pós-Graduação em Educação, Universidade de Brasília, Brasília, 2013.

POLLACK, M. Memória e Identidade Social. Estudos Históricos, v. 5, n.10, p.200-212, 1992.

RYAN, R. L. Exploring the effects of Environmental Experience on attachment to Urban Natural Areas. Environment and Behavior, USA, v.37, n. 3, p. 1-41, 2005.

ROCHA, L. B. O centro da cidade de Itabuna: trajetória, signos e significados. Ilhéus: Editus, 2003.

ROMERO, M. A. B. Arquitetura bioclimática do espaço público. Brasília: Editora da UnB, 2001.

SANCHOTENE, M. C. C. Conceitos e composição do índice de áreas verdes; Boletim Informativo da Sociedade Brasileira de Arborização Urbana, Piracicaba, n. 1, p. 4-9, 2004. 
